\title{
STUDYING EPILEPSY TO UNDERSTAND BIPOLAR DISORDER?
}

\section{Marco Mula MD PhD}

Atkinson Morley Regional Neuroscience Centre, St George's University Hospitals NHS Foundation Trust and Institute of Medical and Biomedical Sciences, St George's University of London, United Kingdom

\section{Correspondence:}

Dr. Marco Mula MD PhD

Atkinson Morley Regional Neuroscience Centre

St George's University Hospitals NHS Foundation Trust

Blackshaw Road London SW17 0QT

United Kingdom

Tel: $+44(0) 2087254107$

Fax $+44(0) 2087254591$

Email: mmula@sgul.ac.uk

Key words: epilepsy, bipolar disorder, antiepileptic drugs, kindling, depression, temperament, mania 
The modern conceptualization of bipolar disorder goes back to 1854, when Jules Baillarger described to the French Imperial Academy of Medicine, a biphasic mental illness causing mood oscillations between mania and depression that he called "folie à double forme" (dual-form insanity) (1). The same year, Jean-Pierre Falret presented a case of what was essentially the same disorder but named "folie circulaire" (circular insanity) (2). After that, Emil Kraepelin described the natural course of bipolar patients and coined the term "manic depressive psychosis" (3). The Kraepelinian hierarchical and categorical approach to mental illnesses remained influential for many years and definitely contributed to the theoretical conceptualisation of DSM. Over time, the need for a dimensional approach to psychopathology became evident and clinicians became aware that not only threshold-level manifestations, but also atypical symptoms, behavioural traits and temperamental features had to be taken into account (4). The novelty of the dimensional approach is that psychiatric symptoms may occur throughout the lifetime, sometimes in isolation rather than as part of a temporally circumscribed clinical syndrome. These symptoms are not pathological per se and they don't encompass a categorical diagnosis but rather represent the biological or constitutional core of personality features that refer to reactivity, variability, and intensity of emotional dispositions. However, they obviously impact on the natural course of a specific disease in terms of response to treatment and prognosis. This concept is particularly evident for bipolar symptoms (5). Current categorical systems define a manic episode as characterized by a period of at least one week where an elevated, expansive or unusually irritable mood, as well as notably persistent goal-directed activity is present. However, it is now recognised that DSM criteria do not adequately capture the phenomenological nuances of mania (6) and unrecognized bipolar symptoms represent a common source of treatment resistant depression (7) and suicidality during antidepressant drug treatment (8).

An important point raised by this Targeted Review (9) is that the previous assumption that mood instability was uncommon in epilepsy was wrong. It is now evident that bipolar symptoms are not rare in patients with epilepsy and can be exacerbated in some circumstances. A cross sectional study showed that the irritable temperament is more frequent in epilepsy as compared to healthy controls (10). Although less defined than other temperaments, the irritable one is much closer to the mixed aspects of bipolarity. Mixed symptoms, especially mixed irritability, are often difficult to recognise by non-expert clinicians and one of the key elements is represented by rapid mood changes, hostility and irritability while taking medications other than those prescribed for mood problems or during medical illnesses. Interestingly enough, increased irritability/aggressive behaviour with medications other than those prescribed for mood problems is a well-known phenomenon in epilepsy (11). Thus, there is no doubt that subthreshold bipolar symptoms, in particular mixed-irritability, are present in patients with epilepsy and probably explain most of the psychiatric adverse effects of antiepileptic drugs. In addition, emerging data suggests that mixed irritability is associated with increased hospitalization (12) and high suicide risk in patients with mood disorders (13). It is thus possible that bipolar symptoms may also account for the increased suicidality risk in patients with epilepsy. Further studies on this topic are clearly needed.

What is the natural consequence of this observation? Should we screen patients with epilepsy for bipolar symptoms? As discussed in this Targeted Review current screening instruments are not satisfactory with a clear tendency to overdiagnose but from a clinical perspective, psychiatric reactions to antiepileptic drugs, especially counterpolar ones (i.e. irritability, agitation or psychotic 
symptoms with sedative/GABAergic antiepileptic drugs) should represent a red flag for an underlying bipolarity.

The relationship between epilepsy and bipolar disorder rises also the question whether the two disorders are neurobiologically connected and whether neurobiological findings in the epilepsy field can help our understanding of the neurobiology of bipolar disorder and vice versa. In 1976, Robert Post published his seminal paper on kindling on the American Journal of Psychiatry (14) where he eloquently discussed how the repetitive subthreshold stimulation of the limbic system could be eventually associated with spontaneous seizures and behavioural manifestations. After 40 years, his observations are still contemporary and fascinating but there are a number of limitations when the kindling model is translated into practice. Apart from the number of species-specific issues related to the kindling phenomenon per se, it is now clear that animal models of kindling used in the epilepsy field are not satisfactory to predict potential mood stabilizing properties of a specific compound. For example, the amygdala-kindled rat was initially considered a good animal model to test potential anti-manic drugs (15) but it became apparent over time that this is not the case. In fact, compounds like GBP, which shows good results in that animal model (16), failed dramatically in clinical trials of acute mania (17). In this regard, it has to be acknowledged that it is only superficially understood how antiepileptic drugs mediate a mood-stabilizing activity (18). Furthermore, antiepileptic drugs present a clear class effect in terms of preventing seizures but this does not seem to be the case for mood stabilisation. The neurobiology of bipolar disorder is still unknown and most importantly there are no universally accepted animal models (19), limiting the possibility of screening for new therapeutic agents. This Targeted Review discusses possible genetic mechanisms shared by bipolar disorder and epilepsy but much remains unknown regarding the contribution of genetic versus environmental variables in the development of both conditions. Epidemiological studies show that patients with bipolar disorders are at increased risk of unprovoked seizures and epilepsy. In some cases this seems to be due to alcohol abuse or illicit drug use (20), but other studies confirmed an increased risk in bipolar patients even after adjusting for potential confounders (21-22).

Current data clearly suggest a connexion between epilepsy and bipolarity. The nature of such a relationship is still obscure. New insights into the neurobiology of psychiatric manifestations of epilepsy will probably shed light into the neurobiology of mood control and polarity.

\section{Acknowledgment and conflict of interest}

MM received consultancy fees from UCB Pharma, Eisai and Pfizer. He has also received supports from Special Products Ltd and is currently serving as Associate Editor of Epilepsy \& Behavior.

\section{References}

1. Baillarger J. Folie à double forme. Annales médico-psychologiques du système nerveux. Masson, Paris 1854

2. Sadler MJ. Falret's discovery: the origin of the concept of bipolar affective illness. Translated by M. J. Sedler and Eric C. Dessain. Am J Psychiatry. 1983;140: 1127-33. 
3. Goodwin F K, Jamison K. Manic-Depressive Illness, 2nd ed. Oxford University Press, New York 2007

4. Cassano GB, Dell'Osso L, Frank E, Miniati M, Fagiolini A, Shear K, Pini S, Maser J. The bipolar spectrum: a clinical reality in search of diagnostic criteria and an assessment methodology. J. Affect. Disord. 1999;54:319-328.

5. Cassano GB, Mula M, Rucci P, Miniati M, Frank E, Kupfer DJ, Oppo A, Calugi S, Maggi L, Gibbons R, Fagiolini A. The structure of lifetime manic-hypomanic spectrum. J Affect Disord. 2009;112(13):59-70

6. Benazzi F. Challenging DSM-IV criteria for hypomania: diagnosing based on number of nopriority symptoms. Eur. Psychiatry. 2007;22:99-103.

7. Sharma V, Khan M, Smith A. A closer look at treatment resistant depression: is it due to a bipolar diathesis? J Affect Disord. 2005;84:251-7.

8. Rihmer Z, Akiskal H. Do antidepressants $\mathrm{t}(\mathrm{h})$ reat(en) depressives? Toward a clinically judicious formulation of the antidepressant-suicidality FDA advisory in light of declining national suicide statistics from many countries. J Affect Disord. 2006;94:3-13.

9. Knott S, Forty L, Craddock N, Thomas RH. Epilepsy and bipolar disorder. Epilepsy \& Behav 2015;

10. Erdoğan Taycan S, Taycan O. Affective temperament profiles and clinical correlates in patients with epilepsy: a link from mood disorders. J Affect Disord. 2014;164:1-4.

11. Mula M, Agrawal N, Mustafa Z, Mohanalingham K, Cock HR, Lozsadi DA, von Oertzen TJ. Selfreported aggressiveness during treatment with levetiracetam correlates with depression. Epilepsy Behav. 2015;45:64-7.

12. Perugi G, Akiskal HS, Micheli C, Toni C, Madaro D. Clinical characterization of depressive mixed state in bipolar-I patients: Pisa-San Diego collaboration. J. Affect. Disord. 2001;67:105-114.

13. Dilsaver SC, Chen YW, Swann AC, Shoaib AM. Krajewski KJ. Suicidality in patients with pure and depressive mania. Am J Psychiatry. 1994;151:1312-1315.

14. Post RM, Kopanda RT. Cocaine, kindling, and psychosis. Am J Psychiatry. 1976;133:627-34.

15. Amann B, Grunze H. Neurochemical underpinnings in bipolar disorder and epilepsy. Epilepsia 2005;46 Suppl 4:26-30

16. Potschka H, Feuerstein TJ, Loscher W. Gabapentin-lactam, a close analogue of the anticonvulsant gabapentin, exerts convulsant activity in amygdala kindled rats. Naunyn Schmiedebergs Arch Pharmacol 2000;361:200-205.

17. Cipriani A, Barbui C, Salanti G, Rendell J, Brown R, Stockton S, Purgato M, Spineli LM, Goodwin GM, Geddes JR. Comparative efficacy and acceptability of antimanic drugs in acute mania: a multiple-treatments meta-analysis. Lancet. 2011;378:1306-15.

18. Mula M. Investigating psychotropic properties of antiepileptic drugs. Expert Rev Neurother. 2013;13:639-46.

19. Machado-Vieira R, Kapczinski F, Soares JC. Perspectives for the development of animal models of bipolar disorder. Prog Neuropsychopharmacol Biol Psychiatry 2004;28:209-224

20. Bakken IJ, Revdal E, Nesvåg R, Brenner E, Knudsen GP, Surén P, Ghaderi S, Gunnes N, Magnus P, Reichborn-Kjennerud T, Camilla Stoltenberg, Trogstad LI, Håberg SE, Brodtkorb E. Substance use disorders and psychotic disorders in epilepsy: a population-based registry study. Epilepsy Res. 2014;108:1435-43.

21. Martin RC, Faught E, Richman J, Funkhouser E, Kim Y, Clements K, Pisu M. Psychiatric and neurologic risk factors for incident cases of new-onset epilepsy in older adults: data from U.S. Medicare beneficiaries. Epilepsia. 2014;55(7):1120-7. 
22. Adelöw C, Andersson T, Ahlbom A, Tomson T. Hospitalization for psychiatric disorders before and after onset of unprovoked seizures/epilepsy. Neurology. 2012;78:396-401. 